\title{
Experimental Study on Spray and Combustion Characteristics of Biodiesel Blends
}

\author{
Seang-Wock Lee ${ }^{1}$ and Doo-Sung Baik ${ }^{2 *}$ \\ ${ }^{1}$ Graduate School of Automotive Engineering, Kookmin University, Seoul, Korea \\ ${ }^{2}$ Computer-aided Mechanical Design Engineering, Daejin University, \\ Pocheon, Korea \\ *dsbaik@daejin.ac.kr
}

\begin{abstract}
This research was conducted on experimental analysis of spray and combustion characteristics of six different biodiesels in a constant chamber using a common-rail injection system. The processes of atomization and flame developments were visualized by using a high digital camera under two different injection pressures. The pressure changes were measured by a piezometer pressure sensor, and combustion processes were analyzed by computing heat release rates. From these results, it was concluded that highly pressurized injection accelerated atomization of fuels and caused to shorten ignition delay period and thus improved overall combustion characteristics. In particular, the oxygen contents included in biodiesel accelerated combustion conditions. Furthermore, these quantitative and reliable data of biodiesel fuels which might be useful in supporting their applicability and establishing emission reduction measure in future as well.
\end{abstract}

Keywords: Biodiesel, Compressed ignition, Ignition delay, Constant volume Chamber $(C V C)$, Common-rail direct injection, Ultra low sulfur diesel (ULSD)

\section{Introduction}

Research on alternative energy resources and environmental pollution has been conducted actively to seek for solution for expensive oil price and global environmental problems which become important issues in international society. Particularly, it is necessary to reduce $\mathrm{NO}_{\mathrm{x}}$ and PM simultaneously and effectively since the effects of $\mathrm{NO}_{\mathrm{x}}$ and $\mathrm{PM}$ emitted from diesel engine are fatal to human body. On the other hand, bio-diesel fuel has been observed as a low emission alternative fuel in the aspect of harmful emission reduction and climate change agreements. However, biodiesel fuels have their unfavorable properties at a low temperature and cause problems in fueling system. Cold performance test of six different biodiesel blends in a passenger car and a light duty truck was made to investigate cold performance and cold filter plugging point (CFPP) in property characteristics of biodiesel fuel blends [1]. It is usually produced from animal fats or vegetable oils by trans-esterification reaction. Biodiesel fuel includes lower sulfur and higher oxygen content than conventional diesel fuel. The included oxygen may facilitate the combustion process and contribute in reducing pollutant emissions from diesel engine. Furthermore biodiesel fuel can be applied to current diesel engines without special engine modification. As an alternative fuel, biodiesel fuel has a great potential of reducing $\mathrm{CO}, \mathrm{CO}_{2}, \mathrm{HC}, \mathrm{PM}, \mathrm{SO}_{\mathrm{x}}$ and $\mathrm{PAH}$ emissions nevertheless there are slight increase of brake specific fuel consumption and $\mathrm{NO}_{\mathrm{x}}$ emission [2,3]. Flame development and soot formation processes of biodiesel fuel spray were studied [4]. The effect of biodiesel and 
its blends (BD10 BD80) were investigated on the engine performance, emission and combustion characteristics by applying waste cooking oil methyl ester (WCO-ME) [5]. Biodiesel (fatty and methyl ester) was used to investigate the characteristics of engine performance and emissions characteristics [6]. Meanwhile, a combustion test on an engine was conducted by applying 11 different kinds of vegetable oils [7]. Biodiesel fuel was applied to small and full sized vehicles and studied the power and emissions [8]. Research on the behavior and atomization characteristics of biodiesel fuel was conducted [9-15]. This study was conducted on combustion and emission characteristics in order to investigate its feasibility as an alternative fuel. The experiment was done in a constant volume chamber by conventional diesel fuel with six different of biodiesel fuels and the results of emissions and combustion characteristics were compared and analyzed with each other blends.

\section{Experimental Apparatus and Method}

\subsection{Experimental apparatus}

A constant volume chamber was applied for the visualization of spray and combustion characteristics of a compressed ignition type engine and its bore and width were $86.2 \mathrm{~mm}$ and $39 \mathrm{~mm}$. A high speed digital camera was installed to photograph actual shapes of fuel spray and diffusion of flame. An intake valve, an exhaust valve, a pressure sensor, a spark plug and two visual windows of bore $120 \mathrm{~mm}$ and thickness $25 \mathrm{~mm}$ at both sides for photographing were installed as CVC peripheral equipment. Residual exhaust gases were removed using a vacuum pump and collected in a decompression tank (See Figure 1). A high speed digital camera was used to photograph the spray and flame development of biodiesel fuel and the corresponding photographing speed was set up to $4000 \mathrm{fps}$. Also, the pressure change was measured by a piezometer pressure sensor and combustion processes were analyzed by computing the heat release rates. The data of combustion pressure were secured using DAQ (Data Acquisition: DAQ Card-6024E) and all the signals of ignition and photographing timings were controlled by Code vision AVR C language. After the completion of combustion process Horiba potable gas analyzer (MEXA-554JK) was applied. The experimental conditions were shown in Table 1.

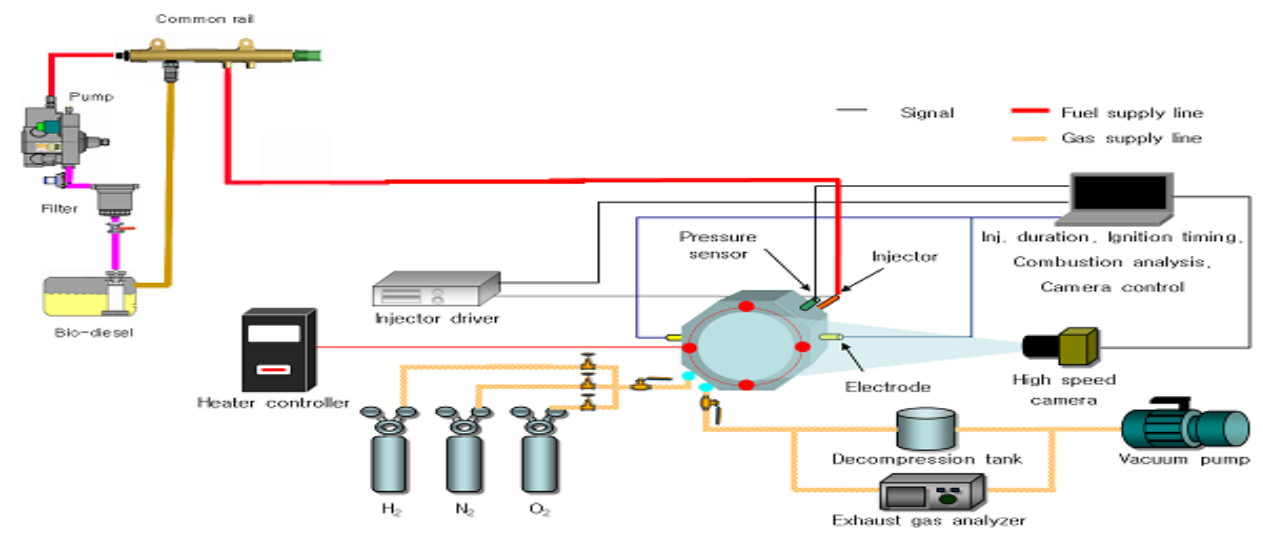

Figure 1. Schematic diagram of experimental apparatus 
Table 1. Experimental conditions

Table 2. Properties of biodiesel (BD20) blends for test *HBD:Hydro-Treated Biodiesel , WCO:Waste Cooking Oil

\begin{tabular}{|c|c|}
\hline Bore $\times$ Width $(\mathrm{mm})$ & $86.2 \times 39$ \\
\hline Displacement $\left(\mathrm{cm}^{3}\right)$ & 228 \\
\hline Fuel Delivery & Direct Injection \\
\hline Injection Pressure $(\mathrm{MPa})$ & 60,100 \\
\hline Injection Duration(ms) & 2.5 \\
\hline Ambient $\mathrm{O}_{2}$ Concentration & $\begin{array}{c}2 \% \text { vol.(spray) } 21 \% \\
\text { vol. (combustion) }\end{array}$ \\
\hline Ambient Pressure $(\mathrm{MPa})$ & 2 \\
\hline Nozzle dia. $(\mathrm{mm})$ & 0.134 \\
\hline
\end{tabular}

\begin{tabular}{|c|r|r|r|r|}
\hline Blends & PourPoint & \multicolumn{1}{|c|}{$\begin{array}{c}\text { Flash } \\
\text { point } \\
\left({ }^{\circ} \mathrm{C}\right)\end{array}$} & $\begin{array}{c}\text { CFPP }( \\
\left.{ }^{\circ} \mathrm{C}\right)\end{array}$ & \multicolumn{1}{c|}{ CN } \\
\hline ULSD & -12 & 59 & -8 & 55 \\
\hline Soybean & -10 & 64 & -8 & 50 \\
\hline Jatropha & -10 & 63 & -8 & 54 \\
\hline Palm & -8 & 63 & -8 & 54 \\
\hline WCO & -10 & 64 & -8 & 56 \\
\hline HBD & -15 & 62 & -10 & 56 \\
\hline Rapeseed & -10 & 63 & -8 & 54 \\
\hline
\end{tabular}

\subsection{Experimental method}

Biodiesel fuel was sprayed within a very short period of time, which was much faster as the injected pressure increased. Spray visualization was made in order to photograph instantly high resolution pictures in a darkroom. For the visualization of combustion processes hydrogen fuel was supplied to a constant volume chamber just before biodiesel fuel was injected in order to provide high atmosphere temperature and pressure inside the chamber (Figure 2). The experiments were conducted under the conditions of atmosphere pressure $2 \mathrm{MPa}$ and the injection pressures were fixed to $60 \mathrm{MPa}$ and $100 \mathrm{MPa}$. And also injection period was fixed to $2.5 \mathrm{~ms}$ during the whole processes of the experiment.

\subsection{Applied biodiesel blends}

Six kinds of biodiesel fuel blended by 5 and $20 \%$ ratios were used. The biodiesel blends were kept at $300 \mathrm{~K}$ for 30 days and as the result of inspection, there was no separation of liquid phase except for some sediment in jatropha, palm and rapeseed oils. Table 2 represents the properties of biodiesel fuels. The index of their CFPP and pour point represent properties quantitatively at cold weather.

\section{Results and Discussion}

\subsection{Spray visualization}

The liquid spray images are shown in Figure 3 for BD5 and BD20 at two injection pressures to illustrate the effects of biodiesel on spray development or tip penetration distances. More fuel impingements are found for BD20 than BD5. The stronger fuel impingement for BD20 is attributed to the longer penetration since biodiesel has a higher boiling point with a low evaporation and the density of biodiesel is slightly higher than ULSD (or BD0). And when injection pressure increases, the spray reaches faster to the bottom of a combustion chamber in all the cases. This is mostly due to the more liquid penetration which accelerates the fuel droplets to move faster. 


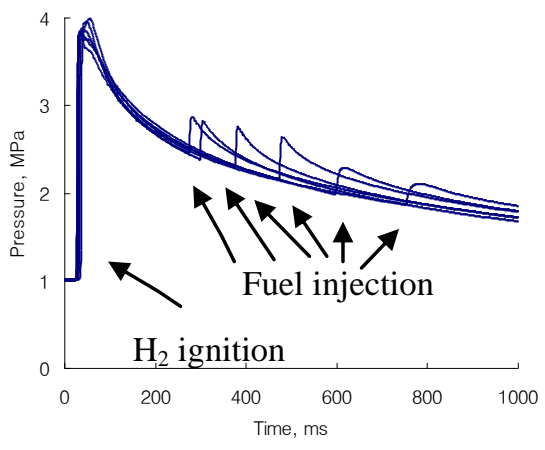

Figure 2. Pre-ignition of hydrogen and injection

\begin{tabular}{|c|c|c|c|c|}
\hline & $\begin{array}{r}5 \% \\
60 \mathrm{MPa} \\
\end{array}$ & $\begin{array}{r}20 \% \\
60 \mathrm{MPa} \\
\end{array}$ & $\begin{array}{r}5 \% \\
100 \mathrm{MPa} \\
\end{array}$ & $\begin{array}{r}20 \% \\
100 \mathrm{MPa} \\
\end{array}$ \\
\hline ULSD & 1711 & 1111 & 1111 & 111 \\
\hline Jatropha & 111 & 111 & & 11 \\
\hline Soybean & 11 & 111 & 11 & 111 \\
\hline WCO & 111 & 111 & 1 & 11 \\
\hline HBD & 11 & 171 & 11 & 1711 \\
\hline Rapeseed & 11 & 1711 & 11 & 1111 \\
\hline Palm & 11 & 111 & & \\
\hline
\end{tabular}

Figure 3. Spray tip penetration of biodiesel blends at injection pressures

\subsection{Combustion visualization}

The combustion images for BD0 and BD20 are shown in Figure 4 and 5 under two different injection pressures. The injection timings are varied from $0.1 \mathrm{~ms}$ to $2.5 \mathrm{~ms}$. The flames are developed in the direction of spray and then collided at a cylinder wall and diffused to inside a combustion cylinder. The differences between BD0 and BD20 are ignition timing and luminosity. The initial flame occurs later for BD20. The luminosity of BD20 is lower than that of BD0 and the flame of BD20 is not as distributed as that of BD0. The local flame luminosity for BD20 is mainly due to the slow evaporation rate of BD20. The cetane number for $\mathrm{BD} 20$ is less than BD0 and it contributes to the ignition timing significantly. BD0 has the highest soot luminosity in the combustion flame, which is due to no oxygen in the pure fuel compared with biodiesel blends. For biodiesel blends, the soot luminosity is attributed to the trade-off between fuel volatility and oxygen. From late flames, there are some local flames on the chamber wall for BD20. For the BD20, there are some local early flame near the spray tip location in the CVC. This is attributed that BD20 fuel has longer ignition delay compared with BD0. And also the flame of last stage is burnt-out much faster for BD20 than BD0 due to its oxygen content. When injection pressure increases to $100 \mathrm{MPa}$, the ignition started earlier due to the stronger fuel impingement. The differences between $\mathrm{BD} 0$ and BD20 are ignition and luminosity. Initial flame for BD0 occurs later for BD20. The luminosity of BD20 is much lower than that of BD0. The combustion pressure and heat release rates as the function of time for BD0 and BD20 are shown Figures 6 9. The diagram of pressure and heat release rates were different due to the various ignition timings since longer ignition delay allows much more mixtures of fuel and air and induces stronger jet impingement during the combustion processes. HBD and $\mathrm{WCO}$ have shorter ignition delays compared to others. And $\mathrm{HBD}$ emitted less $\mathrm{CO}, \mathrm{HC}$ and $\mathrm{NO}_{\mathrm{x}}$ compared to others. This is due to the characteristics of HBD fuel which was manufactured by the process in which oxygen was removed and hydrogen was added instead. 


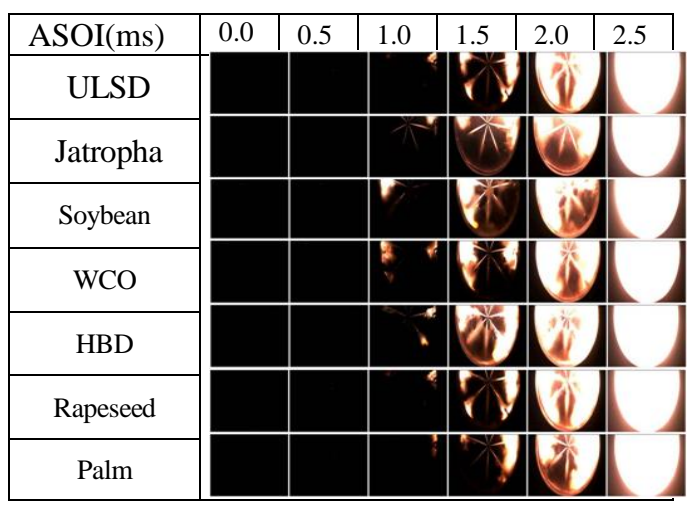

Figure 4. Flame visualization at $60 \mathrm{Mpa}$

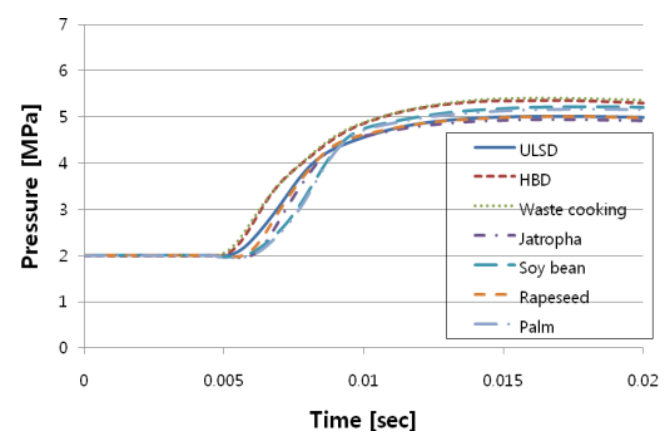

Figure 6. Pressure diagram of BD20 $\left(P_{\text {inj }}=60 \mathrm{Mpa}\right)$

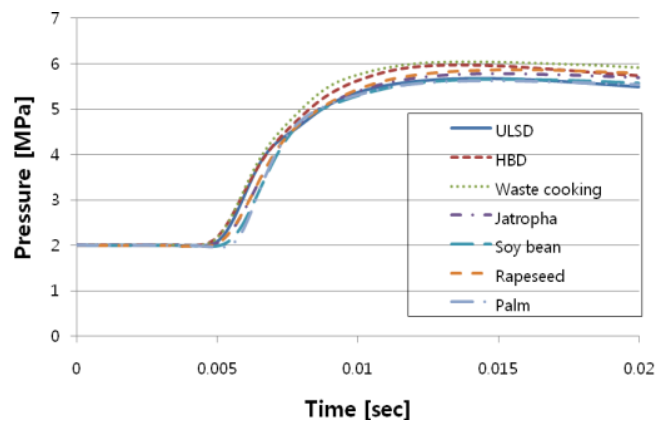

Figure 8. Pressure diagram of BD20 ( $\left.P_{\text {inj }}=100 \mathrm{MPa}\right)$

\begin{tabular}{|c|l|l|l|l|l|l|}
\hline ASOI(ms) & 0.0 & 0.5 & 1.0 & 1.5 & 2.0 & 2.5 \\
\hline ULSD & & & & & \\
\hline Jatropha & & & & & \\
\hline Soybean & & & & & \\
\hline WCO & & & & & \\
\hline HBD & & & & & & \\
\hline Rapeseed & & & & & & \\
\hline Palm & & & & & & \\
\hline
\end{tabular}

Figure 5. Flame visualization at $100 \mathrm{MPa}$

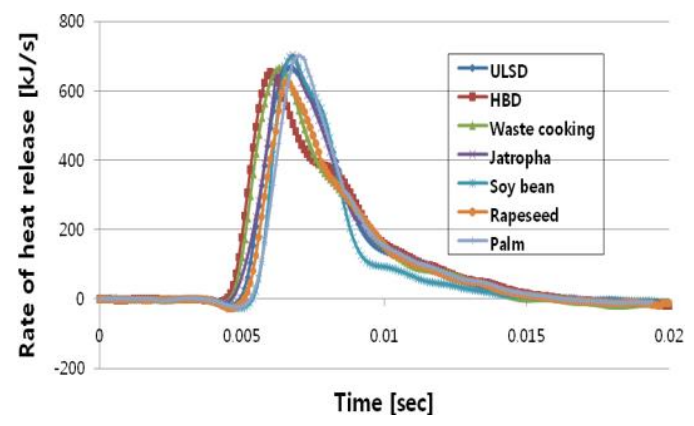

Figure 7. Heat release rates of BD20 $\left(P_{\text {inj }}=60 \mathrm{MPa}\right)$

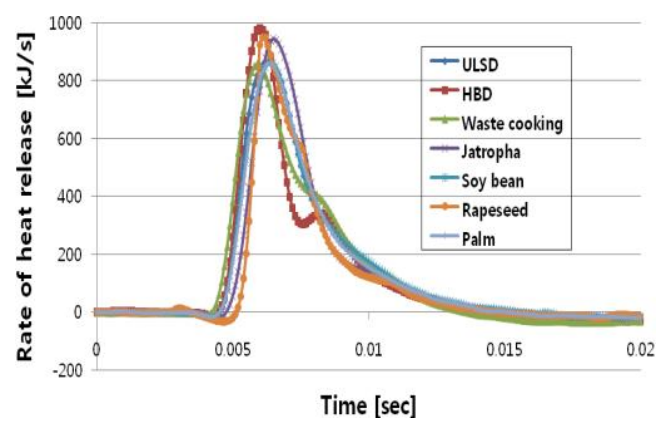

Figure 9. Heat release rates of BD20 ( $\left.P_{\text {inj }}=100 M P a\right)$ 


\section{Conclusions}

In summary, this study aims to investigate the characteristics on spray and combustions of six kinds of biodiesel blends (BD20) by applying common-rail system in a constant volume chamber. Jet spray, combustion images, combustion process and heat release rates were important parameter in determining the characteristics of biodiesel blends and some important are made. Biodiesel has a higher boiling point and causes longer penetration and stronger fuel impingement with the increase of biodiesel content. The cetane numbers for biodiesel blends play an important role for the combustion performance of six biodiesel blends (BD20) and especially cetane number in $\mathrm{HBD}$ and $\mathrm{WCO}$ are higher than other blends. $\mathrm{NO}_{\mathrm{x}}$ emission increases with the increase of biodiesel contents due to it oxygen content and retarded injection timing. However, an early injection strategy may contribute to reduce $\mathrm{NO}_{\mathrm{x}}$ emission significantly when biodiesel blends were used to conventional diesel engines.

\section{Acknowledgements}

This work was supported by the Daejin University Research Grants in 2014.

\section{References}

[1] R. Anand, G. Kannan, S. Nagarajan and S. Velmathi, "Performance Emission and Combustion Characteristics of A Diesel Engine Fueled with Biodiesel Produced from Waste Cooking Oil”, SAE paper, 2010-01-0478 (2010).

[2] A. Demirbas, "Relationships derived from physical properties of vegetable oil and biodiesel fuels", Fuel, vol. 87, (2008), pp. 1743-1748.

[3] T. Fang, Y. C. Lin, T. M. Foong and C. F. Lee, "Biodiesel combustion in an optical HSDI Diesel engine under low load premixed combustion conditions", Fuel, vol. 88, (2009), pp. 2154-2162.

[4] C. E. Goering, A. Schwab, M. Dougherty, M. Pryde and A. Heakin, "Fuel properties of eleven vegetable fuels", Trans. ASAE, vol. 25, (1982), pp. 1743-17848.

[5] R. Joshi and M. Pegg, "Flow properties of biodiesel fuel blended at low temperatures", Fuel, vol. 86, (2007), pp. 143-151.

[6] B. Kegl, "Numerical analysis of injection characteristics using biodiesel fuel", Fuel, 85 (2006), pp. 2377-2387.

[7] B. Kegl and A. Hribernik, "Experimental analysis of injection characteristics using biodiesel fuel", Energy Fuels, vol. 220, (2006), pp. 2239-2248.

[8] B. Kegl, "Biodiesel usage at low temperature", Fuel, vol. 87, (2008), pp. 1306-1307.

[9] J. K. Kim, E. S. Yim, C. H. Jung and C. S. Han, "Cold performance of various biodiesel fuel blends at low temperature”, Int. J. Automotive Technology, vol. 13, no. 2, (2012), pp. 293-300.

[10] G. Koszalka, J. Hunicz and A. Niewczas, "A comparison of performance and emissions of engine fueled with diesel and biodiesel”, SAE paper, 2010-01-1474 (2010).

[11] O. A. Kuti, W. Zhang and K. Nishida, "Effect of injection pressure on ignition, flame development and soot formation process of biodiesel fuel spray", SAE paper, 2010-32-0053 (2010).

[12] Ryu, "A study on the exhaust emission reduction characteristics by using biodiesel fuel in the compressed injection engine”, KSAE Spring Proceeding, vol. 1, (2012), pp. 526-531.

[13] K. W. Scholl and S. C. Sorenson, "Combustion of soybean oil Methyl in a direct injection diesel engine", SAE paper, 930934 (1993).

[14] S. H. Park and S. C. Kwon, "Macroscopic behavior and atomization characteristics of biodiesel fuels", Trans. Of KSAE, vol. 12, no. 6, (2012), pp. 23-29.

[15] D.-S. Baik and S.-W. Lee, "Application of biodiesel fuels in diesel engine, Proceedings of International Workshops on Bioscience and Medical Research”, (2013) December 11-13; Jeju Island, Korea. 


\section{Authors}

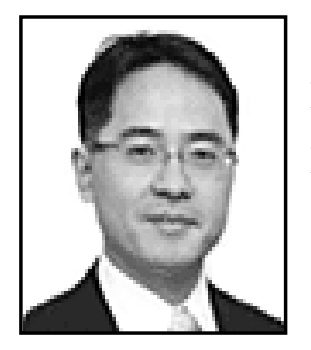

\section{Seang-Wock Lee}

Prof. Kookmin University

Ph. D. Waseda University

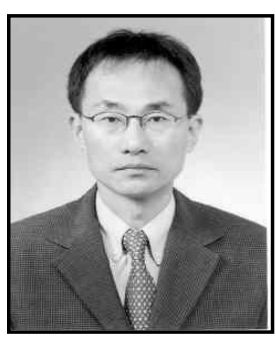

\section{Doo-Sung Baik}

Prof. Daejin University

Ph.D. Wichita State University 
International Journal of Bio-Science and Bio-Technology Vol.6, No.2 (2014) 